\title{
O "TREINAMENTO COMO MEIO DE "SEGURANÇA" NAS EMPRÊSAS
}

\section{MARCOS PONTUAL}

Quando ocorrem mudanças, na emprêsa, pode o treinamento contribuir para a manutenção da «segurança" do indivíduo?

Os indivíduos, independentemente de sexo, idade, nacionalidade. cultura e "status" econômico e social, têm como necessidade psicológica fundamental a "segurança". Sentir-se "seguro" segnifica sentir o resultado de uma personalidade bem ajustada.

De acôrdo com FlEMING (1), a obtenção e a manutenção da segurança, nos sêres humanos, dependem do desenvolvimento de três sentimentos: o de aceitação, o de sucesso e o de liberdade.

O sentimento de aceitação vai-se desenvolvendo à medida que os indivíduos recebem admiração e apreciação de outros indivíduos ou grupos e, também, quando oferecem admiração e apreciação através de compromissos de lealdade e de contribuições de responsabilidade.

Na vida interna da emprêsa, o dar e receber admiração e apreciação e o contribuir com responsabilidade e lealdade dependem dos esforços sociais e técnicos com os quais esta,

MARCOS PONTUAL - Co-Diretor Técnico do Programa da Comissão Brasileira-Americana de Educação Industrial em São Paulo. Assistente de Administração de Pessoal do Curso de Engenharia de Produção da Escola Politécnica da Universidade de S. Paulo.

(1) - C. M. Fleming, «Adolescence Psychological Needs and Attitudes», - Adolescence, - Routledge and Kegan, Paul Ltd.. Londres - pg. 44 . 
através de sua estrutura básica, permite o desenvolvimento individual, na certeza de que é êle parte integrante do seu objetivo de negócios.

A emprêsa, nas suas relações externas, dá admiração e apreciação pelas suas contribuições de responsabilidade e lealdade, através do cumprimento exato de seu objetivo de negócios, o qual implica na sua integração eficiente na comunidade a que pertence. Ela recebe, então, como retribuição, o prestígio vindo de seus consumidores e fornecedores.

O segundo sentimento, o de sucesso, depende dos resultados das contribuições de responsabilidade e do "aventurar-se" nas experiências que se tornam possíveis, à medida que se processa o crescimento econômico e técnico-cultural. As emprêsas progridem e, assim, nas suas relações externas, o sucesso vai sendo medido pelo resultado dos novos investimentos nos vários campos compreendidos nas diretrizes que regem seu objetivo de negócios. No caso, é primordial que os indivíduos que a compõem e cujo crescimento não só é paralelo, como também é causa dêsse progresso, possam "viver" tudo que leve à experiência de sucesso.

o terceiro sentimento, o de liberdade, deve existir para que indivíduo e emprêsa experimentem compreensão ou "insight" e possam redefinir e reformular sua atuação, com vistas à consecução dos objetivos a que se propuseram.

Os sentimentos de segurança de indivíduos e da emprêsa são resultados da reciprocidade de atuação dos mesmos, cabendo, no entanto, à última, por fôrça da responsabilidade final, a promoção dos meios de consegui-los.

A necessidade fundamental de "segurança" é imutável. Entretanto, os conceitos sôbre as condições que a garantem mudam, em virtude das modificações que ocorrem nas influências que existem sôbre essas condições. Tais conceitos envolvem, principalmente, as relações industriais.

\section{Relações Industriais e as Situações de Mudança}

$\mathrm{O}$ conceito de relações industriais decorre de dois importantes grupos de influência. O primeiro é o das condições de tra- 
balho sempre em modificação; o emprêgo em massa e as grandes fôrças de trabalho têm dificultado as relações pessoais entre patrão e empregado, anteriormente mais próximas e mais intimas.

A automatização, a rotina e os processos gerais de operação industrial que transformaram a maior parte das tarefas em monótonas e repetitivas, diminuíram muito as possibilidades do empregado de experimentar e tomar iniciativas decorrentes de seu próprio julgamento e, portanto, de sua personalidade.

Sempre que possível, os trabalhos que demandam habilidade humana têm sido eliminados para reduzir o custo alto de mão-de-obra. Como conseqüência, a "motivação" e o interêsse que o trabalho desperta, ou pode criar, diminuem, diminuindo as possibilidades de manifestações de admiração e apreciação, de contribuição de responsabilidade e lealdade, de "aventuras" que tragam sucessos e de liberdade para melhor compreensão, abalando-se o sentimento de "segurança" dos indivíduos que trabalham e, por conseguinte, da emprêsa como um todo.

O segundo grupo de influências que se exercem, igualmente, na atitude do empregador e do empregado, constitui-se das influências externas à emprêsa. Devem ser devidamente estimados o crescente desenvolvimento da inteligência das populações e a conseqüiente necessidade de independência intelectual em todos os níveis da mão-de-obra, em vista das solicitações culturais cada vez maiores trazidas pelo rádio, televisão, cinema, modernos métodos de publicidade e propaganda, o que, se por um lado é um desenvolvimento altamente desejável com vistas à dignidade humana e à consolidação da democracia, por outro requer uma revisão constante dos conceitos e uma atenção cada vez mais cuidadosa para com as relações industriais.

Os dois grupos de influência referidos, quer separadamente, quer interagindo, constituem para a emprêsa e para seus com- 
R.A.E.

ponentes freqüientes situações de mudança, que devem ser prevenidas ou corrigidas.

\section{As situações de Mudança e o Treinamento}

As mudanças constituem problemas de produção porque determinam insucessos iniciais, nas tentativas de lhes fazer face, feitas pelos indivíduos ou setores de uma organização. Esses insucessos iniciais interferem na produção, passando a ser, pois, problemas de produção. A psicologia de aprendizagem afirma que aprender é reagir, como um todo, a uma situação que se nos apresenta e que, por não conseguirmos resolver, constitui um insucesso inicial; assim, quando reagimos para resolvê-la, modificamos o comportamento. Sabe-se que a educação, ao visar o desenvolvimento individual, procura, através de suas várias sistematizações ou classes de instrução, dirigir essa reação de aprender. Por outro lado, ensino é a direção da aprendizagem, o modo de apresentação da instrução, o método. Em relação às mudanças da emprêsa de negócios, o indivíduo, ressalvada sempre sua condição de dignidade humana, tem que estar integrado no objetivo de produção. Assim, deve levar-se em conta a importância de separar-se do conceito de educação o conceito de treinamento, sendo êste último um processo que busca modificar o comportamento, com vistas à produção. Indiscutivelmente, no entanto, educação e treinamento são processos correlatos. Admitindo-se que gerência é o conjunto de responsáveis pela produção, pode-se perfeitamente acompanhar a conceituação de ROSS POLLOCK (2) de que treinamento é o esfôrço planejado de gerência, para obter modificações no comportamento de indivíduos, grupos e organizações, com vistas à produção. Estes tendem a resistir às moditicações que lhes são impostas, mas, mesmo assim, sempre se modificam.

O treinamento, ao modificar o comportamento, modifica-o não apenas tècnicamente, mas também nas atitudes e convicções. Aquêles que treinam devem, portanto, evidenciar

(2) - Ross Pollock, «A Philosophy of Training», Journal of the American Society of Training Directors, Nov. 1959, vol. 13, n. ${ }^{\circ}$ 11, pg. 13. 
atitudes e convicções humanas em harmonia com as "politicas" da emprêsa e seus objetivos básicos, o que significa estarem elas "visando" essas políticas e objetivos.

Por isso mesmo, todos os níveis de gerência, do presidente ao supervisor de menor responsabilidade, são níveis de treinamento. Assim sendo e tendo em vista a responsabilidade final própria de cada gerente, fica implícita, por parte dos mesmos, a necessidade do conhecimento das melhores técnicas de treinamento, a fim de que o máximo em resultados seja obtido através da harmonia entre o assunto de treinamento, as políticas e objetivos da emprêsa e a prática diária do trabalho.

o "moral" alto de qualquer indivíduo ou grupo não o pre dispõe necessàriamente a estar integrado nos planos e desejos da gerência e, por isso mesmo, o "moral" alto nem sempre resulta em alta produtividade.

Assim sendo, o treinamento tem que ser um esfôrço constante para transformar o bom "moral" em motivação e isso só é possivel num ambiente favorável. Será difícil ter um ambiente de motivação quando existem oposições importantes a algum aspecto das condições de trabalho. Uma oposição mínima, em têrmos de reação, são as perguntas. Um dos trabalhos mais importantes do treinamento é o de apresentar respostas de forma clara e convincente para garantir sua compreensão e aceitação.

\section{o Desenvolvimento do Treinamento}

A linha mestra do treinamento são os fatos que fundamentam e esclarecem o problema de produção. Esse problema é aquilo que interfere com a produção; é tudo o que, como vimos, causa um insucesso inicial para $o$ indivíduo, para $o$ grupo ou para a emprêsa. Os problemas de produção podem ser identificados por se apresentarem inesperadamente, porque se vão tornado gradualmente evidentes, ou porque são estimados ou previstos. Por exemplo, o contrôle de qualidade revela grande percentagem de rejeição de um certo produto; a produção está abaixo da capacidade prevista, uma expansão ou uma nova linha de produção está para ser iniciada. 
Identificado o problema de produção, é necessário identificar, nesse problema, as necessidades de treinamento. Sòmente a obtenção de todos os fatos, através de todos os setores da emprêsa, permitirá uma análise dos mesmos para indicar se poderão ser solucionados pelo treinamento. Deve-se ter sempre em mente que o treinamento resolve uma parte do problema de produção, que poderá ser maior ou menor, conforme demonstre a análise dos fatos.

$O$ acesso a tôdas as fontes da obtenção de fatos da emprêsa quer dizer acesso a tôda a emprêsa, quer dizer gerência por si, ou representada pelo "staff" de treinamento e quer dizer, ainda, aceitação, por parte de todos os componentes da emprêsa, da necessidade dessa obtenção.

As necessidades de treinamento identificam-se, pois, pela análise de todos os fatos e a decisão sôbre o que treinar, quem utilizar para o treinamento, quais os métodos a ser empregados, qual o tempo a ser despendido etc. só poderá ser tomada após o conhecimento total das circunstâncias do problema, uma vez que cada um dêsses elementos deve ser flexivel, nas suas várias características, de acôrdo com essas circunstâncias. Quando o treinamento não é considerado com essa flexibilidade, a estrutura informal da emprêsa poderá chamá-lo de "escolinha", apelido êsse que é sintoma de uma inadequação indesejável e improdutiva.

A fim de ilustrar nossa análise, será examinado, a seguir, o exemplo de um problema de produção colhido numa emprêsa brasileira e tratado pelo sistema de "Desenvolvimento de Programas de Treinamento" - PD, uma das fases do método de supervisão TWI ("Training Within Industry") (3).

\section{Problema - Ampliação da Linha de Fabricação de Regula- dores de Voltagem}

A programação atual estabelece uma produção mensal de 5.000 unidades para a linha de reguladores de voltagem. A produção está em tôrno de 1.200 unidades semanais, ou seja, 4.800 (ou pouco mais) por mês.

(3) - Problema colhido pelo engenheirando Marcos Leite de Souza, sob orientação do autor. 
Para apurar as causas dessa deficiência, o departamento de produção resolve fazer um estudo da linha, mas a gerência comunica, ao mesmo tempo, sua intenção de aumentar para 8.000 a produção mensal da linha, dentro de 3 meses, e para 12.000 , futuramente.

Assim, o departamento de produção encarrega um seu engenheiro de projetar uma linha completamente nova para fazer face a êsse nôvo programa. Estudando a linha atual, o engenheiro verifica que, para o funcionamento da nova linha, basta subdividir algumas operações, estabelecer maior número de locais de trabalho e agrupá-los ao longo de uma esteira móvel. Verifica, também, que o problema principal da linha é o banco de testes. Com base em suas observações, anota o seguinte :

1 - O banco de testes é responsável pela operação mais importante da linha, que é a regulagem mecânica e elétrica do aparelho. $O$ operador toma um aparelho, coloca-o no banco para medir a voltagem e amperagem sob diferentes condições. Essa operação é rápida e simples. Retira o aparelho do banco, mantendo-o na bancada, e faz todos os acertos necessários, usando chaves de fenda, alicates etc. (operação manual leve).

Mede novamente a voltagem e amperagem e coloca o aparelho num aquecedor situado a seu lado. Espera 45 minutos (trabalhando em outras unidades), até que o aparelho atinja a temperatura necessária ao teste a quente. Aí repete as operações que havia feito a frio. Deixa, então, o aparelho esfriar ao lado e faz depois uma repassagem a frio. Geralmente, após essa terceira regulagem, - aparelho é colocado nas condições especificadas. Só raramente é necessário nova regulagem a quente (e depois dessa, sempre haverá outra re passagem a frio).

2 - Existem dois bancos funcionando na linha atual; um termina um regulador cada $3,85 \mathrm{~min}$. O outro termina um cada 5,62 min. Os bancos são 
iguais, devendo-se a diferença dos tempos à menor destreza do operador do segundo banco, mais nôvo no serviço.

3 - O segundo operador ainda não aprendeu alguns pormenores e "manhas" do teste e da regulagem, encontrando má vontade por parte do primeiro para lhe dar os ensinamentos necessários.

4 - Para atingir a produção de 8.000 aparelhos por mês, a linha deve trabalhar sob o ritmo de 0,74 unidades por minuto (ou seja, uma unidade cada 1,35 min.). Trabalhando com os 2 bancos, cada um dêles deveria, então, produzir uma unidade cada 2,70 min. o que é impossível com o método em uso. O engenheiro fêz, então, um estudo dessas operações e chegøu a uma solução com 3 bancos, sendo que o primeiro só faz a regulagem a frio, o segundo a quente e o terceiro a repassagem. As experiências com o nôvo método mostraram ser possível chegar-se até cêrca de 10.000 aparelhos por mês, com operadores práticos. Para isso, deve-se gastar cêrca de Cr $\$ 500.000,00$ num banco nôvo e empregar mais um operador. Mantendo o método atual, só é possível atingir a meta de 8.000 reguladores por mês com 4 bancos, ou seja, gastando $\operatorname{Cr} \$ 1.000 .000,00$ para os dois novos bancos e empregando mais dois operadores.

Observa-se, que, no quadro II as colunas sôbre "qual a melhor maneira de execução", "quem deve treinar", "quando iniciar e por quanto tempo" e "onde" vão sendo preenchidas com soluções adequadas a êsse plano, observando-se especialmente que são três os indivíduos que se vão encarregar de executar o treinamento (engenheiro de produto, engenheiro encarregado da nova linha e mestre da linha), havendo entre êles diferenças hierárquicas, culturais e funcionais e não tendo nenhum dêles funções específicas de treinamento. Observa-se, ainda, que, mesmo sendo um plano calculado para 7 horas, no total, envolverá a alta gerência pelo apoio concreto que the deve ser dado. Envolverá, também, a gerência média e os operários, bem como providências de "linha" e de "asses- 


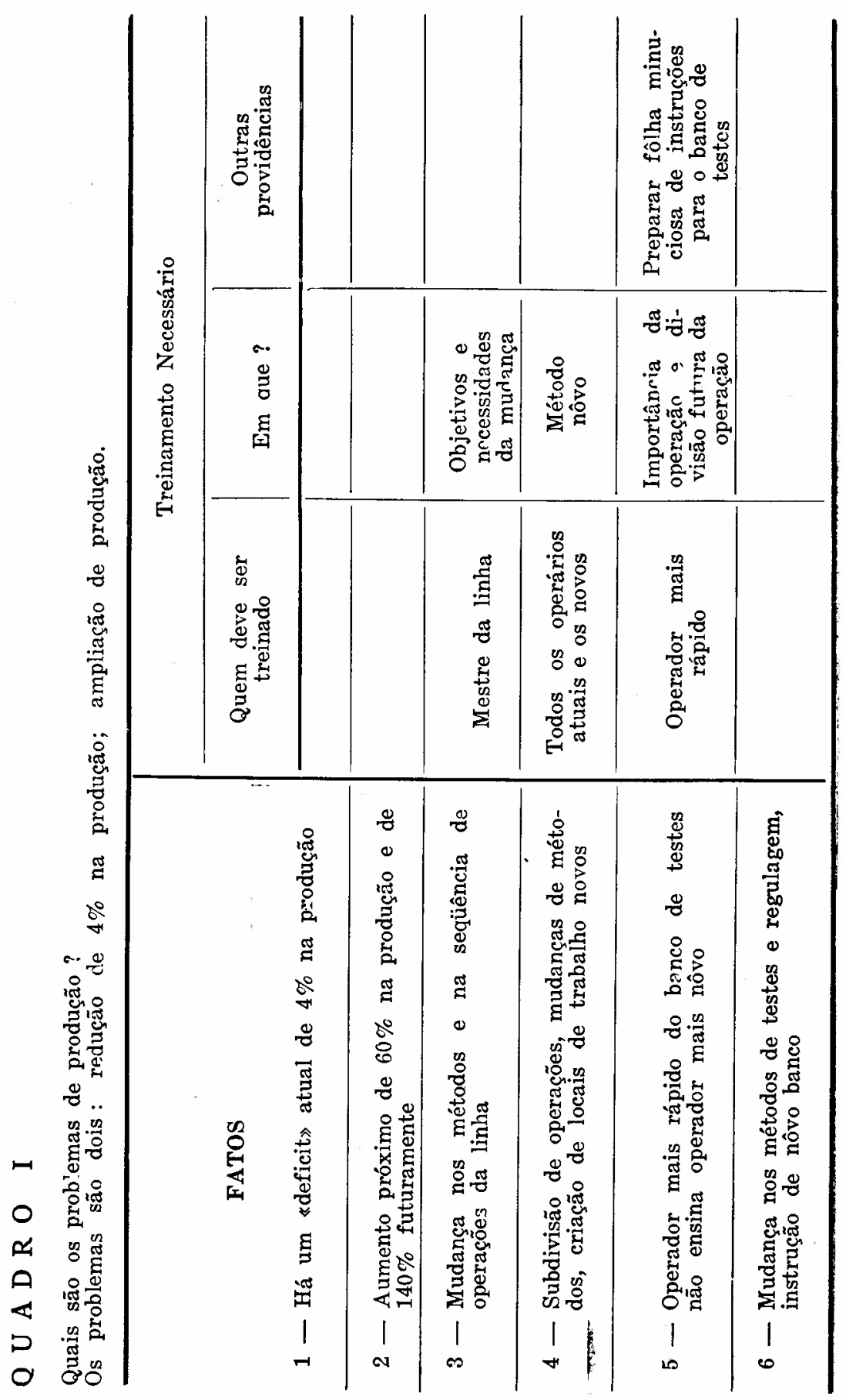




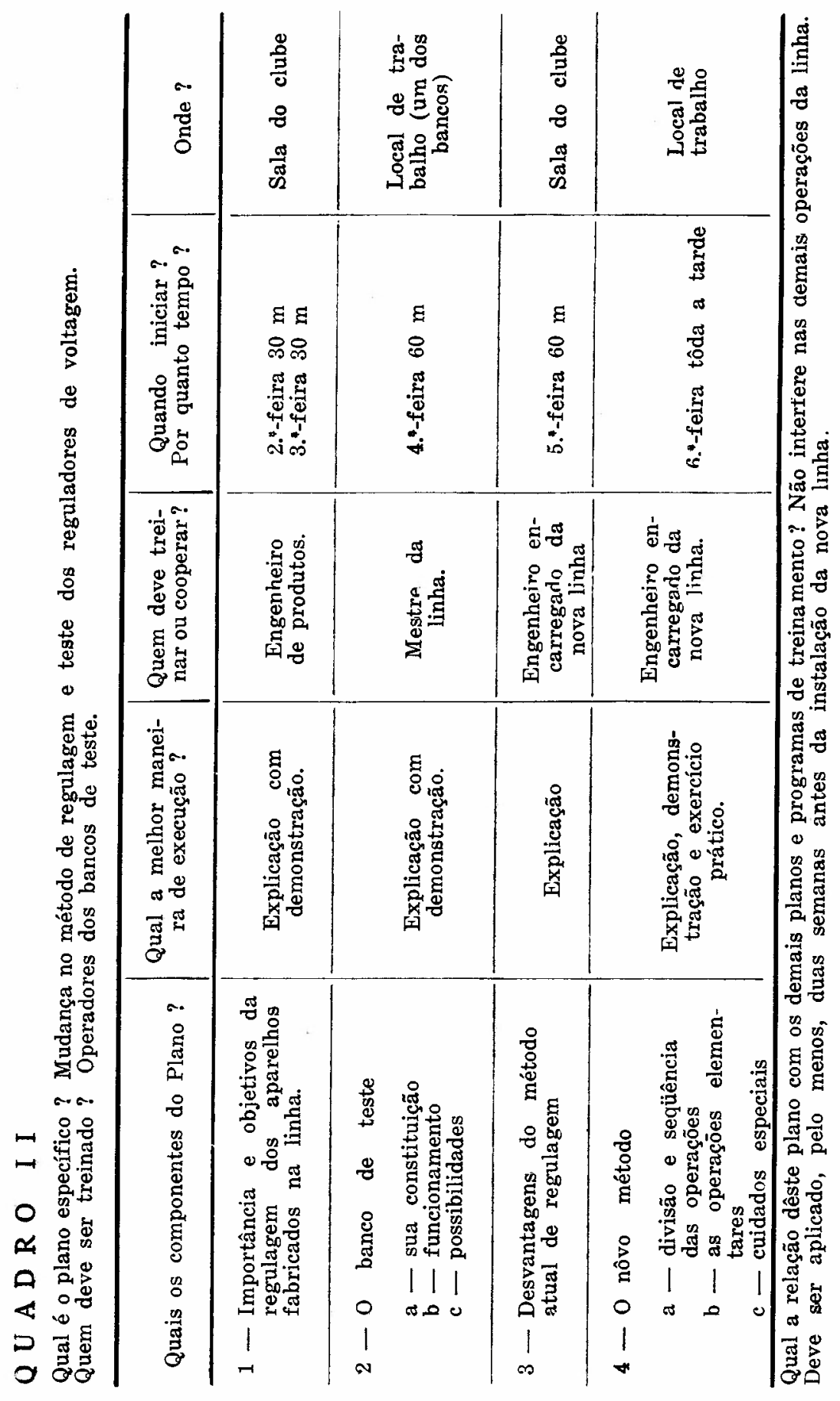


soria". Assim sendo, na determinação de necessidades de treinamento e escolha dos métodos para fazer face às mesmas, é importante levar em conta que a alta gerência precisa conhecer e compreender os fatos do problema. A gerência média e a supervisão de linha precisam compreender como êsses fatos afetam as operações e o que fazer a respeito dêles. Os executadores precisam aprender e compreender o significado dos fatos para que o treinamento seja útil em têrmos de cooperação com as políticas da emprêsa, procedimentos, métodos e requisitos de trabalho.

No exemplo acima, os fatos que indicaram o treinamento a ser desenvolvido evidenciaram a diminuição da "segurança" da emprêsa. Como pode, então, o administrador fechar os olhos para essa realidade? Como pode certificar-se do valor do treinamento?

\section{Os Resultados do Treinamento}

O treinamento é investimento e, como tal, deve apresentar resultados que o justifiquem. Na opinião de DONALD KIR KPATRIK (4), o progresso na avaliação dêsses resultados tem sido lento porque, em grande parte das tentativas de avaliá-lo, como, por exemplo, em programas de redução de acidentes e de custo, poucas vêzes foi possível isolar outras variáveis que possam atuar.

O critério a ser seguido, no entanto, deverá cobrir quatro fases importantes :

a - resultados quanto à reação de aceitação do elemento que está sendo treinado;

b - resultados específicos de aprendizagem;

c - resultados quanto à modificação do comportamento no trabalho;

$\mathrm{d}$ - resultados quanto ao objetivo específico do programa.

(4) - Donald L. Kirkpatrick, kTechniques for Evaluating Training Programs», Journal of the American Society of Training Directors, nov. 1959 , vol. $13, \mathrm{n} \cdot{ }^{p} 11, \mathrm{pg}$. 3 . 
Quaisquer que sejam as técnicas utilizadas para essas fases, assim como quando da obtenção dos fatos, é necessário o apoio integral da gerência para que, na medida do possível, tôdas as variáveis possam ser identificadas, porque, como vemos, tôdas elas são profundamente ligadas à "segurança" do indivíduo e da emprêsa.

Supervisão é obtenção da realização de um trabalho e é nos vários níveis de gerência que ela se realiza. A dinâmica da vida das emprêsas supõe, implìcitamente, novas técnicas, novas rotinas, novas decisões, comunicações, admissões, promoções, transferências de pessoas, novas atribuições e relações humanas.

Todos êsses elementos constituem situações de mudança e, por conseguinte, necessidades de treinamento.

A existência de uma "política" de treinamento, na organização, devidamente regulamentada, identificando necessidades, planejando, executando e controlando resultados, significa a incorporação do treinamento como um dos instrumentos de "segurança" da organização. 